\title{
Pandemic inequality: new realities and prospects
}

\author{
Mayya Valerianovna Dubovik ${ }^{1}$ \\ Plekhanov Russian University of Economics, Department of Economic Theory, Moscow, Russia
}

\begin{abstract}
This paper investigates the emergence of factors contributing to pandemic inequality. The pandemic itself is a completely novel factor, and it is associated with high uncertainty. Methodologically, this study builds upon sociological, economic, and psychological theories of inequality; these theories are elaborated by a combination of dialectical and causal analysis. The paper presents short overview of prior research into factors of pandemic and post-pandemic inequality in the context of the changing labor market; it further analyzes major trends and patterns of such inequality in order to identify the key causes and challenges of the situation today. It focuses on the need to help workers and businesses adapt to the irreversible processes of the post-pandemic world, to change the macroeconomic policy on many levels of the administrative hierarchy. The results of this study could lay the foundations for studying the behavior of workers in the labor market; they should also be accounted for by public agencies responsible for welfare programs intended to curb the pandemic inequality. The theoretical and practical contributions hereof lies in substantiation of the need to optimize the priorities of macroeconomic policies, to implement them competently in the fight against poverty, to balance the costs and benefits of labor market transformation, and to devise novel social policy mechanisms.
\end{abstract}

Keywords: socio-economic inequality, "pandemic" inequality, macroeconomic policy

\section{Introduction}

The shock that the pandemic brought to all aspects of life has polarized the society on all levels; the change that ensues can no longer be ignored by the macroeconomic pandemic policy makers. In Russia, $10 \%$ of the population has monthly income of or below 100 thousand rubles; the lower decile is $\leq 10$ thousand rubles. The income gap is unacceptable. The pandemic made inequality and discrepancy even worse. The goal hereof was to identify new challenges and risks that far exceed all of the previous negative factors in gravity, contribute to polarization and to pandemic inequality. The paper analyzes global trends in the development of various forms of pandemic inequality, highlights the trajectories of their evolution, and proposes steps to mitigate their effects.

\footnotetext{
${ }^{1}$ Corresponding author: mvdubovik@gmail.com
} 


\section{$2 \quad$ Materials and methods}

At the heart of social inequality is economic inequality, although this is an egg-vs-chicken kind of relationship. These sets can be called fuzzy; however, their intersection creates novel forms of inequality that arise from today's macroeconomic shocks, whether endogenous or exogenous. Thus, today's reality is overshadowed by the so-called pandemic inequality, a new phenomenon that needs to be understood and calls for the creation of new tools to mitigate it.

Piketty claims that economic inequality is inherent to capitalism [1, 2]. Although he claims that this trend was suspended in the times of Word Wars, one can disagree. Apparently, today's conflicts and wars only exacerbate economic inequality, whether on the national, regional, or individual scale [3].

Economists and sociologists who pen papers on economics or work in business point to different causes of economic inequality, which might be due to the fact that these two groups pursue different interests. Thus, Ancient Greek philosophers would speak in defense of slaveowners and justify social and property-based differentiation $[4,5]$. Nobel Prize winner and inequality researcher Joseph Stiglitz sees the primary cause of inequality in the pursuit of privileged rent ownership backed by market and political power. He highlights such political and institutional factors as staff remuneration systems, models of supply and demand in the labor market [6].

Authors $[7,8]$ believe inequality to be mainly attributable to the rapid change in various technologies, whether those involved in creating a product or used to promote it (logistic, marketing, and consumption applications). Change concerns the organization of production, business processes, and management.

Universal digitalization, one of the latest tech developments, exacerbates disparity in the labor market in the short and medium term, as demand for high-skill labor increases, whereas low-skill labor is falling out of grace, a situation that calls for novel, advanced programs for staff (re)training. Digitalization eliminates low-skill, mechanical labor; these workers lose their income and join the poor strata [9-11]. In [12] was reported that up to $86 \%$ of restaurant jobs, up to $75 \%$ of jobs in retail, and up to $59 \%$ of entertainment jobs can be automated as soon as by 2035 .

Institutional factors of inequality include, according to [13-16], the weakening of trade unions. Trade unions have ever lesser influence on employee-employer relationships, which evolve; thus, trade unions can no longer mitigate economic inequality as extensively as they earlier could. Immigration rates and demand for workforce have declined amidst the pandemic; many jobs have been moved to home offices.

Some authors point to the mistakes that governments and public authorities made when applying a variety of macroeconomic policy instruments, which contributed to inequality [17].

Schwab and Malleret [12] note a new form of ownership as a factor of pandemic inequality: total control over the inner world of the people, pandemic slavery of a kind.

Economic inequality does not boil down to wage alone. Bureau of Economic Analysis reports that over the past decade, benefits and premiums payable by employers have increased more than twelvefold and come to account for most of employees' income. A broad range of allowances and reimbursements are payable as productivity incentives, overtime bonuses, work-on-vacation payments, insurance premiums, pension fund contributions, etc. This category of remuneration alone has grown by $>10 \%$. 
Social inequality today manifests itself in health disparity and unequal access to medical care. There is no denying that at the core of any such disparity is unequal education and income. Some researchers believe that health quality and income / wealth correlate. Marmot [18] has shown every year of schooling to improve individual's health [19]. Similar but weaker correlation is found between income and health. Deaton A. describes inequality in the variety of its manifestations as affected by geographical, economic, and social status; the author presents a case study of two families to illustrate their position [20].

Kollier [21] describes inequality that has a geographic dimension to it, stems from the place of residence, correlates with education, views of morality, and cultural background. He describes the confrontation and opposition of people in the following dichotomies: residents of central locations vs residents on the periphery; poor, undereducated people with little to no opportunities vs educated, professional people who are tolerant to various social minorities, make up the ruling class, and trust in the government and in the state.

Inflation is an important driver of inequality and poverty. In Russia, inflation reached $6 \%$ in May 2021, whereas nominal average pension was indexed by $5.5 \%$ and totaled 15,806 rubles. Thus, real income, in particular pensions, dropped by $0.5 \%$, which could be critical for retirees and other low-income people.

\section{$3 \quad$ Results}

Thus, whereas earlier one's origin and inherited wealth would make them part of the elite, now it is the professionalism and individual competitiveness of workers that enable them to join the ruling class.

Polarization of people working online and offline is another specific trait of pandemic inequality. Not everyone has the skills, equipment, mental resilience, and soft skills to work online. The stringent conditions of the pandemic contribute to income disparity and social differentiation. COVID-19 has brought significant gender changes to the labor market.

Any recession is associated with large-scale staff cuts, and unemployment usually hits women first. However, the pandemic-related crisis in the labor market does not discriminate by gender. Immigrant males have had it worst, as, e.g., in Russia, immigrants have less labor opportunities in lockdown and are more likely to lose their jobs. Similar downward trends in the employment of male immigrants are noted in [22]. Besides, low-skill immigrants are not needed online, and they are forced to go home. Men are known to be less tolerant to job loss and are more likely to show signs of deviant behavior as a result of being sacked [23].

\section{Discussion}

When exposed to technological change, companies take different spots in the global value chains (GVCs), which predetermines their domination or subordination in their respective industries, thus affecting their proportion of added value. Areas, regions, and countries where such companies are headquartered become prioritized. However, in light of the pandemic and associated lockdowns, GVCs have to be "undeployed", evacuated from their regions, and relocalized within a single country or locality, which does affect local development. One example is the United States, whose production chains were moved far to Asia and India only to be brought back home urgently. Such repositioning restructures the labor market and exacerbates inequality. 
The availability of, and access to, digital tech in these difficult times depends on household income and varies by country or region, which only fuels this new digital divide. Discrepancy in education hinders any attempt to address the deformation of the labor market, as it has always been. Higher education does not necessarily make one a desirable employee. This mismatch of labor supply and productivity creates inequality pertaining to education.

The development of several vaccines against a variety of coronavirus strains is an important milestone of the 21 st century's science and technology. However, access to vaccination varies from country to country, which is perhaps the most important highlight of what we call pandemic inequality. Interestingly, countries that offer multiple vaccines for free are also slow to progress in this respect. Russia is a vivid example of this trend. Duke University reports AstraZeneca to be the \#1 vaccine manufacturer, and the EU and the US to be the major buyers that have purchased over $50 \%$ of all doses. China refers to this policy as "vaccine protectionism". Developed economies have allocated $\sim 17 \%$ of GDP to fight the pandemic, middle-income countries are at $4 \%$, whereas the least developed nations can only afford $1.6 \%$ [25].

For every three persons whose employer pays medical insurance in the upper quartile, there is only one recipient of such payments in the lower quartile, income-wise. That being said, in the lower income quartier, only 1 out of 4 persons eligible for such payments will actually receive any compared to 3 out of 4 in the upper quartile. Availability of bonuses and other supplementary remunerations varies from industry to industry. Bonuses are the way high-tech companies retain valuable employees. In reality, economic inequality is deeper, as it should be seen through the lens of total income, which includes not only salaries, but also income generated from assets, property, etc. FRS reports a 10:1 ratio of financial asset owners (upper vs lower decile) [24].

As for the instruments of fiscal and monetary policies, they have often been misused due to ignorance of national traits, the specifics of the phase of the cycle and time. On the one hand, global economic inequality was reinforced in the aftermath of WW2, as the world became split into two opposing parties once the winning nations were done splitting the spoils of war. On the other hand, further public regulations failed to create a fair state of welfare for all. For instance, a social state does not necessarily manage to address inequality. Middle class, deprived of welfare and benefits, becomes poor. Financial elites abuse the availability of the rent to accumulate wealth and assets; they only grow wealthier over time.

Research of the Institute of Health and Equity focuses on the root causes of inequality in health and how this gap could be bridged. However, there are a few contradictions here. Thus, long-lived residents of the Caucasus Mountains are not necessarily educated and/or rich. The rich can be just as powerless against diseases as the poor; Steve Jobs can attest to that. Apparently, people can succumb to COVID-19 regardless of their age and social status.

\section{Conclusion}

The pandemic left no country, no social stratum, no aspect of life unaffected. Richer nations have been funding the sectors that create and maintain human capital: health, education, and culture; they have thus been able to spend more to mitigate the effects of the pandemic. However, pandemic inequality has worsened the existing forms of inequality, exacerbated social tensions, and weakened the physical and mental capabilities of man. 
The coronavirus shock has contributed to the gender-related and geographical manifestations of unemployment; immigration rates dropped, and those who have lost their jobs are facing ever greater psychological issues in light of such uncertainty.

The new experience of governments and health systems should help tackle the challenges of tomorrow and mitigate the risks of the upcoming waves of the pandemic. To that end, we need consolidated international effort and must focus on digitalization of public services, which in the long term will improve the well-being of a broader demographic while also enabling secure collection of people's data.

In pursuit of social security, governments must ensure access to medical insurance or universal healthcare in order to tackle pandemic inequality.

The reported study was funded by RFBR, project number 20-010-00578.

\section{References}

1. T. Piketty, Capital in Twenty-One Century. (Harvard University Press, Boston, 2014)

2. F. Novokmet, T. Piketty, G. Zucman, NBER Work Paper Ser, 23712 (2017). https://doi.org/10.3386/w23712

3. M.V. Dubovik, Int J Civil Eng Techn, 10(2), 1704-1711 (2019)

4. Plato, Gosudarstvo [The State]. (St. Petersburg, 2006)

5. Aristotle, Politika [The Policy]. (ACT, Moscow, 2010)

6. E. Seçilmiş, Ekonomik Yaklaşım, 27(100), 223-235 (2016). https://doi.org/10.5455/ey.35942

7. Y. Kalantzis, Y. Kambayashi, S. Lechevarier, Labour, 26(4), 514-541 (2012). https://doi.org/10.2139/ssrn.2153618

8. E. Brynjolfsson, A. McAfee, M. Spence, Foreign Aff, 93(4), 44-53 (2014)

9. E.L. Groshen, H.J. Holzer, The Russell Sage Found J Soc Sci, 5(5), 1-19 (2019). https://doi.org/10.7758/RSF.2019.5.5.01

10. C. Goldin, L.F. Katz, The Race Between Education and Technology. (Harvard University Press, Cambridge, 2008). https://doi.org/10.1086/ahr.114.5.1413

11. A.D. Skills, Science, 344(6186), 843-851 (2014)

12. K. Schwab, T. Malleret, COVID-19: The Great Reset, in World Economic Forum 91-93 route de la Capite CH-1223 Cologny/Geneva Switzerland (2020). https://doi.org/10.1007/s42413-021-00117-7

13. T.A. Kochan, W.T. Kimball, The Russell Sage Found J Soc Sci, 5(5), 88-108. (2019). https://doi.org/10.7758/RSF.2019.5.5.05

14. S. Machin, Res Labor Econ, 43, 329-354 (2016). https://doi.org/10.1108/S0147-912120160000043017

15. H.S. Farber, D. Herbst, I. Kuziemko, S. Naidu, NBER Work Paper Ser, 24587 (2018). https://doi.org/10.3386/w24587

16. J. Sherk, Backgrounder, 2825, 1-17 (2013)

17. L. Mishel, J. Bivens, E. Gould, H. Shierholz, The State of Working America. (Cornell University Press, New York, 2012). https://doi.org/10.7202/1024216ar

18. M. Marmot, et al., Health equity in England: the Marmot Review 10 years on the Health Foundation. (Institute of Health Equity, London, 2020) 
19. D. Cutler, A. Leras-Muney, Education and Health: Evaluating Theories and Evidence, in R.F. Schoeni, J.S. House, G.A. Kaplan, H. Pollack (eds), Making Americans Healthier: Social and Economic Policy as Health Policy. (Russell Sage Foundation New York, 2008)

20. A. Deaton, Rev Austrian Econ 28, $443-447$ (2015). https://doi.org/10.1007/s11138-014-0269-5

21. P. Kollier, The Future of Capitalism. Facing the New Anxieties. (Harper Collins Publishers, 2020)

22. G.J. Borjas, H. Cassidy, NBER Work Paper Ser, 27243 (2020). https://doi.org/10.3386/w27243

23. V. Galasso, et al., NBER Work Paper Ser, 27359 (2020). https://doi.org/10.3386/w27359

24. Board of Governors of the Federal Reserve System. Accessed on: October 2, 2021. [Online]. Available:

https://www.federalreserve.gov/econres/scf/dataviz/scf/chart/\#series:Stock Holdings; emographic:nwcat:population: 1.2.3.4.5:units:median

25. J.L. Dieleman, et al., Lancet, 396, 693-724 (2020).

https://doi.org/https://doi.org/10.1016/S0140-6736(20)30608-5 